\title{
Fractionated stereotactic body radiotherapy for up to five prostate cancer oligometastases: interim outcomes of a prospective clinical trial
}

Patrick Bowden ${ }^{\star, 1}$, Andrew W. See ${ }^{1}$, Mark Frydenberg ${ }^{2,3}$, Hodo Haxhimolla ${ }^{4,5}$, Anthony J. Costello $^{6}$, Daniel Moon ${ }^{6,7,8}$, Paul Ruljancich ${ }^{9}$, Jeremy Grummet ${ }^{2,8}$, Alan Crosthwaite ${ }^{9}$, Ganes Pranavan $^{10}$, Justin Peters ${ }^{6,8,11}$, Kevin So ${ }^{1}$, Stella M. Gwini ${ }^{12}$, Dean P. McKenzie ${ }^{8,12}$, Skye Nolan $^{1}$, Lloyd M. L. Smyth ${ }^{1}$, Craig Everitt ${ }^{1}$

${ }^{1}$ Icon Cancer Centre, Richmond, VIC, Australia

${ }^{2}$ Department of Surgery, Monash University, Clayton, VIC, Australia

${ }^{3}$ Australian Urology Associates, Melbourne, VIC, Australia

${ }^{4}$ Department of Urology, The Canberra Hospital, Garran, ACT, Australia

${ }^{5}$ Australian National University, Canberra, ACT, Australia

${ }^{6}$ Department of Surgery, University of Melbourne, Parkville, VIC, Australia

${ }^{7}$ Division of Cancer Surgery, Peter MacCallum Cancer Centre, Melbourne, VIC, Australia

${ }^{8}$ Epworth Healthcare, Richmond, VIC, Australia

${ }^{9}$ Epworth Eastern, Box Hill, VIC, Australia

${ }^{10}$ Department of Medical Oncology, The Canberra Hospital, Garran, ACT, Australia

${ }^{11}$ Department of Urology, Royal Melbourne Hospital, Parkville, VIC, Australia

${ }^{12}$ School of Public Health and Preventive Medicine, Monash University, Clayton, VIC, Australia

This is the author manuscript accepted for publication and has undergone full peer review but has not been through the copyediting, typesetting, pagination and proofreading process, which may lead to differences between this version and the Version of Record. Please cite this article as doi: $10.1002 / \mathrm{ijc} .32509$

This article is protected by copyright. All rights reserved. 
*Corresponding author: Address: Icon Cancer Centre, Level 4, The Epworth Centre, 32 Erin Street, Richmond, 3121. Fax: +61 39936 8269. Email: pat.bowden@icon.team

Conflicts of interest statement: The authors declare no conflicts of interest

Keywords: Androgen deprivation therapy, Oligometastases, Prostate cancer, Stereotactic body radiotherapy

Article category: Research article - Cancer Therapy and Prevention

Novelty \& impact: This is the interim analysis of the largest prospective trial of fractionated stereotactic radiotherapy for oligometastatic prostate cancer. Patients with up to five synchronous oligometastases were included, whereas previous studies typically limit the number of treated lesions to three. PSMA-PET was the predominant staging modality. Outcomes for patients with four to five initial lesions did not differ significantly from those with one to three lesions in terms of treatment escalation free survival.

Abbreviations: ADT, androgen deprivation therapy; ADT-FS, androgen deprivation therapy free survival; $\mathrm{Cl}$, confidence interval; $\mathrm{CT}$, computed tomography; CTCAE, common terminology criteria for adverse events; EBRT, external beam radiotherapy; EQD2, equivalent total dose in two-gray fractions; Gy, gray; GTV, gross tumour volume; HR, hazard

This article is protected by copyright. All rights reserved. 
ratio; IQR, interquartile range; MDT, metastasis directed therapy; OR, odds ratio; PCa, prostate cancer; PET, positron emission tomography; PSA, prostate specific antigen; PSMA, prostate specific membrane antigen; PTV, planning target volume; RP, radical prostatectomy; RT, radiotherapy; SBRT, stereotactic body radiotherapy; TE-FS, treatment escalation free survival

This article is protected by copyright. All rights reserved. 


\section{ABSTRACT}

Stereotactic body radiotherapy (SBRT) can delay escalation to systemic treatment in men with oligometastatic prostate cancer. However, large, prospective studies are still required to evaluate the efficacy of this approach in different patient groups. This is the interim analysis of a prospective, single institution study of men relapsing with up to five synchronous lesions following definitive local treatment for primary prostate cancer. Our aim was to determine the proportion of patients not requiring treatment escalation following SBRT. In total, 199 patients were enrolled to receive fractionated SBRT (50 Gray in 10 fractions) to each visible lesion. Fourteen patients were castration resistant at enrolment. The proportion of patients not requiring treatment escalation two years following SBRT was 51.7\% (95\% Cl: 44.1 59.3\%). The median length of treatment escalation free survival over the entire follow-up period was 27.1 months (95\% Cl; 21.8 - 29.4 months). Prior androgen deprivation therapy (ADT) predicted a significantly lower rate of freedom from treatment escalation at two years compared to no prior $\operatorname{ADT}(\mathrm{OR}=0.21,95 \% \mathrm{Cl}$ : $0.08-0.54, p=0.001)$. There was no difference in the efficacy of SBRT when treating four to five versus one to three initial lesions. A prostate specific antigen (PSA) decline was induced in $75 \%$ of patients, with PSA readings falling to an undetectable level in six patients. No late grade three toxicities were observed. These interim results suggest that SBRT can be used to treat up to five synchronous prostate cancer oligometastases to delay treatment escalation.

This article is protected by copyright. All rights reserved. 


\section{INTRODUCTION}

Systemic treatment with androgen deprivation therapy (ADT) and/or chemotherapy remains at the core of treating metastatic prostate cancer (PCa). ${ }^{1}$ However, metastasis-directed therapy (MDT) has emerged as an alternative approach for a subset of patients with limited metastatic (oligometastatic ${ }^{2}$ ) disease. In this setting, the rationale for MDT is to 1 ) eradicate the cancerous lesion(s), 2) delay exposure to next-line systemic therapy, and 3) delay progression to a castration-resistant state. ${ }^{3}$

Results of the first randomised phase II trial of MDT for oligometastatic prostate cancer were recently published. ${ }^{4}$ MDT (surgery or stereotactic ablative radiotherapy) provided ADT-free survival of 21 months versus 13 months for surveillance among men with up to three $\mathrm{PCa}$ oligometastases. In addition, several relatively small studies demonstrate the efficacy of metastasis-directed radiotherapy to delay the clinical progression of oligometastatic PCa, with minimal adverse effects. ${ }^{5-8}$

Despite these promising results, the subset of patients who will benefit most from MDT has not yet been defined. ${ }^{3}$ Studies powered by large sample sizes are still required to assess the influence of factors such as lesion number, lesion location and hormone-sensitivity on the efficacy of MDT. In addition, previously published studies limit the number of oligometastases treated to three.

This is the interim analysis of a prospective study evaluating fractionated stereotactic body radiotherapy (SBRT) for patients with up to five synchronous oligometastatic PCa lesions. The primary endpoint was the proportion of patients not requiring treatment escalation two years following SBRT. We sought to identify characteristics associated with a better

This article is protected by copyright. All rights reserved. 
response to SBRT. To our knowledge, this is the largest prospective trial of SBRT for oligometastatic PCa.

\section{MATERIALS AND METHODS}

\subsection{Study design and setting}

This was a single centre, single arm, prospective study designed to evaluate the efficacy of SBRT for oligometastatic PCa. The study was approved by the Epworth HealthCare Human Research Ethics Committee, Melbourne, Australia (TRANSFORM: 'RT mediaTed eRAdicatioN of oligometaStatic prostate cancer Following priOr local TReatMent: a prospective phase II study, Australian New Zealand Clinical Trials Registry number ACTRN12618000566235, retrospectively registered). All patients signed informed consent.

\subsection{Participants}

Eligible patients were men with a histologically confirmed diagnosis of prostate cancer, prior definitive local treatment (external beam radiotherapy, brachytherapy, or radical prostatectomy), five or fewer synchronous metastases (N1 and $\mathrm{M} 1 \mathrm{a} / \mathrm{b}$ ) diagnosed on imaging, and ECOG performance status of 0 or 1 . Patients could be ADT-naïve, on a treatment break following prior ADT for metastatic disease, or hormone-refractory and taking ADT at the time of enrolment.

This article is protected by copyright. All rights reserved. 
Patients who had received prior palliative radiotherapy, or who presented with active local disease in the prostate bed on clinical examination or imaging, were excluded from the study.

Serum PSA and testosterone levels were recorded within 6 weeks prior to enrolment. Staging was performed using a combination of magnetic resonance imaging, whole body bone scan and choline positron emission tomography-computed tomography (PET-CT) until September 2014, after which prostate-specific membrane antigen (PSMA)-PET-CT became the primary staging modality. Lesions were documented and classified as local recurrence, lymph node metastases (regional or distant) or bony metastases according to the American Joint Committee on Cancer $7^{\text {th }}$ edition guidelines. ${ }^{9}$

Post-SBRT follow-up with PSA testing, clinical evaluation and toxicity assessment was scheduled for 6 weeks following treatment, three-monthly for two years and then six-monthly thereafter. Patients with a rising PSA were referred for further staging investigations, with the timing of this at clinician discretion.

\subsection{Intervention}

Eligible patients were prescribed a fractionated course of SBRT with the intent to eradicate all visible oligometastatic lesions. The gross tumour volume (GTV) was defined as the tumour visible on the radiotherapy computed tomography (CT) planning scan and the available staging scan(s). A planning target volume (PTV) was contoured for each lesion to account for uncertainties in target position due to internal organ motion or patient movement during treatment. The PTV was an isotropic expansion of the GTV of $5 \mathrm{~mm}$ or $1 \mathrm{~mm}$ for nodal and bony lesions, respectively. The prescription dose for each lesion was 50 Gray (Gy) in 10

This article is protected by copyright. All rights reserved. 
daily fractions, with $90 \%$ of the dose (45 Gy) covering the PTV. An altered fractionation regimen was prescribed in cases where there was overlap with previously delivered radiotherapy fields. In these cases, an equivalent total dose in 2 Gy fractions (EQD2) of at least 60 Gy was maintained $(\alpha / \beta=2)$. Patients presenting with new oligometastases following SBRT were eligible for repeat courses of SBRT given there were no more than five new synchronous lesions and that an EQD2 of at least 60 Gy could be safely delivered to each visible lesion.

SBRT was delivered on the Novalis TX ${ }^{\mathrm{TM}}$ (Varian Medical Systems, Palo Alto, USA) or Truebeam $^{\mathrm{TM}}$ (Varian Medical Systems, Palo Alto, USA) treatment platforms using either dynamic conformal arcs or intensity modulated radiation therapy. The position of all patients was verified prior to each fraction using cone-beam CT and/or dual orthogonal $\mathrm{kV}$ imaging, with corrections made in six degrees using the Exactrac ${ }^{T M}$ (BrainLAB, Munich, Germany) monitoring system and robotic couch.

\subsection{Outcome measurements}

The primary endpoint of this study was the proportion of men not requiring treatment escalation within two years of initial SBRT. Treatment escalation was defined as the commencement of ADT for hormone-naïve patients and those who had prior ADT, the commencement of second-line ADT or chemotherapy for patients with concurrent ADT at enrolment, or palliative radiotherapy. Treatment was escalated at the discretion of the treating clinician(s) based on PSA progression, in-field recurrence following SBRT, progression to polymetastatic disease (greater than five new metastases) or clinician concern at the rate of disease progression despite lack of radiologic progression. Secondary

This article is protected by copyright. All rights reserved. 
endpoints were: (1) length of treatment escalation free survival (TE-FS), (2) change in PSA post-SBRT, and (3) SBRT-related grade three toxicity. Toxicity was assessed using the Common Terminology Criteria for Adverse Events (CTCAE) version 4.0. At the time of the interim analyses, all patients had gone through at least two years of follow-up. Secondary endpoints were assessed using all available data.

\subsection{Statistical analysis}

These are the interim analyses of a five-year follow-up study. The interim analyses employed a conservative alpha set to $p<0.01$, two-tailed, as utilised by Hsueh et al., ${ }^{10}$ for both the primary and secondary endpoints. Ninety-five percent confidence intervals were reported to allow for comparison with other studies.

The number of patients without treatment escalation at two years was reported using percentages together with Clopper-Pearson binomial 95\% confidence intervals. Time to treatment escalation, including the escalations that occurred after two years, was analysed using Kaplan-Meier curves. Association of clinical characteristics with the proportion of men not requiring treatment escalation within two years post-SBRT and the length of TE-FS were analysed using logistic regression ${ }^{11}$ and Cox proportional hazards regression, ${ }^{12}$ respectively. The Cox regression models were checked against the proportional hazards assumption for any significant violations.

Waterfall plots ${ }^{13}$ were employed to show the maximal percent change in PSA from baseline following SBRT for each patient. For patients with a PSA drop following treatment, the maximal percentage change was relative to the lowest PSA reading recorded during the total follow-up period, even if the PSA level eventually increased above baseline. For patients

This article is protected by copyright. All rights reserved. 
who did not record a PSA drop, the maximal PSA change was relative to the highest PSA reading recorded during the total follow-up period. Plots were truncated at a maximum PSA change of $+300 \%$.

Waterfall plots were generated using SAS 9.4 (SAS Institute Incorporated, Cary, North Carolina, 2014), all other statistical and graphical analyses were performed using Stata 15 (Stata Corporation, College Station, Texas, 2017).

\section{RESULTS}

\subsection{Participants}

Two hundred and eight patients were enrolled between April 2014 and April 2016. Nine patients were subsequently excluded from the study. Staging with PSMA-PET-CT was performed for 152 patients (76.4\%). Five patients could not be treated to an EQD2 of 60 Gy due to overlap with previous treatment or PTV size. Two patients did not have all visible oligometastatic lesions treated. One patient did not have metastatic PCa on follow-up restaging scans and one patient had received prior palliative radiotherapy. In total, 199 patients received SBRT. Baseline characteristics for these patients are presented in Table 1. There were no SBRT-related late grade 3 toxicities. One hundred and nine patients $(54.5 \%)$ received a single course of SBRT, 63 (31.7\%) received two courses, 19 (9.5\%) received three courses and $8(4.0 \%)$ received four courses.

The median follow-up time following SBRT was 35.1 months (range: 6.5 - 51.3 months), including patients lost to follow-up. Thirty-three patients $(16.6 \%)$ had received prior ADT. Fourteen patients (7.0\%) were castration-resistant at enrolment and received concurrent

This article is protected by copyright. All rights reserved. 
ADT with SBRT. The initial number of lesions treated was one to three and four to five in 165 (82.9\%) and $34(17.1 \%)$ patients, respectively.

One hundred and seventy-six patients were included for analysis of the primary endpoint. Twelve patients were excluded due to local recurrence in the prostate bed. Six patients developed further oligometastases (five or fewer) following the initial treatment but were not eligible for further SBRT on trial due to overlap with previous radiotherapy fields. Two patients were lost to follow-up, two patients withdrew from the trial, and one patient died prior to two years follow-up.

\subsection{Treatment Escalation}

The proportion of patients not requiring treatment escalation two years following SBRT was 51.7\% (95\% Cl: 44.1 - 59.3\%). Table 2 lists the indications for commencing escalated treatment alongside the treatment type. Rising PSA $(n=43)$ and progression to polymetastatic disease (greater than five synchronous metastases) $(n=36)$ were the predominant reasons for treatment escalation.

Sub-group analyses for treatment-escalation at two years following SBRT are presented in Table 3. Of the patients who had received prior ADT, $6(22.2 \%)$ were free from treatment escalation at two years post-SBRT compared with 79 (58.1\%) of patients with no prior history of ADT, this difference being statistically significant $(p=0.001)$. There was no statistically significant difference between patients treated for one to three versus four to five lesions.

This article is protected by copyright. All rights reserved. 
At the time of last follow up, 105 patients had treatment escalation. The median TE-FS for the cohort was 27.1 months (95\% Cl: 21.8 - 29.4 months). Increasing age (hazard ratio [HR] $=1.39,95 \% \mathrm{Cl}: 1.30-1.48, p<0.001)$ was a statistically significant predictor for treatment escalation. Prior ADT (HR = 1.97, 95\% Cl: $1.22-3.18, p=0.005)$ but not concurrent ADT $(\mathrm{HR}=1.43,95 \% \mathrm{Cl} 0.72-2.84, p=0.30)$ was also associated with poorer TE-FS compared to hormone-naïve patients (Figure $1 \mathrm{~A}$ ). Patients with both bone and nodal lesions were at increased risk of treatment escalation compared to bone-only $(\mathrm{HR}=2.12,95 \% \mathrm{Cl}: 1.12$ 4.02, $p=0.022$ ) (Figure $1 \mathrm{~B}$ ), however, the association was not statistically significant at the $p<0.01$ level. There was no significant difference in TE-FS when comparing the node only and bone only groups $(\mathrm{HR}=0.82,95 \% \mathrm{Cl}$ : $0.51-1.31, p=0.404)$ or when comparing patients with four to five versus one to three initial lesions $(\mathrm{HR}=1.07,95 \% \mathrm{Cl}: 0.68-1.67, p$ $=0.78)($ Figure $1 \mathrm{C})$.

\subsection{PSA response}

A total of 144 patients $(75.0 \%)$ had at least one PSA reading lower than baseline following SBRT, with six patients recording an undetectable PSA level. There were $n=7$ patients with a missing baseline PSA. The maximal PSA change from baseline following treatment is depicted by a waterfall plot in Figure 2 .

At the time of last follow-up, 41 (23.3\%) of 176 patients were free from treatment escalation and had a PSA reading which continued to be below their baseline PSA level. For these 41 patients, the median (IQR) baseline PSA was $1.7(0.9-2.9) \mathrm{ng} / \mathrm{mL}, 33$ were initially staged with PSMA-PET-CT, 33 had one to three lesions initially treated, 30 received SBRT to nodes only and 36 patients had no prior ADT.

This article is protected by copyright. All rights reserved. 


\section{DISCUSSION}

To our knowledge, this is the largest prospective trial of SBRT in the setting of oligometastatic PCa and the first to include patients with up to five initial lesions. Our study showed that over $50 \%$ of patients were free from treatment escalation two years following SBRT with no late grade three toxicities reported. The median TE-FS was 27.1 months. Forty-one patients (23.3\%) had a PSA level lower than baseline in addition to being free from treatment escalation at the time of last follow-up.

The results of our study are comparable to other prospective studies of MDT for up to three oligometastatic PCa lesions. With single fraction stereotactic ablative radiotherapy, Siva et al. ${ }^{5}$ reported that $48 \%$ of patients with no prior history of ADT remained ADT-free at two years. In a study of repeated fractionated SBRT, Decaeststecker et al. ${ }^{8}$ reported a median ADT-free survival (ADT-FS) of 25 months. Ost et al. ${ }^{4}$ found a slightly shorter median ADTfree survival of 21 months, however this study included both surgery and SBRT as the MDT intervention. It should also be noted that our definition of treatment escalation included chemotherapy and palliative radiotherapy in addition to ADT. However, ADT was still the predominant next-line therapy, used in $92(87.6 \%)$ of the 105 patients receiving escalated treatment by the time of most recent follow-up.

An important difference between our study and those previously published is our use of PSMA-PET for disease staging. Three quarters of patients in our study were initially staged using PSMA-PET. These patients had a lower rate of treatment escalation at two years following initial SBRT and slightly longer TE-FS compared to patients who were not initially staged with PSMA-PET, however, these differences were not statistically significant. PSMA- 
PET has excellent sensitivity and specificity ${ }^{14}$ and is a superior modality for detecting PCa lesions compared to choline-based PET imaging. ${ }^{15}$ Based on the responses of a multidisciplinary panel of international experts, PSMA-PET has become the preferred modality for staging biochemically recurrent and advanced PCa. ${ }^{16}$. With PSMA-PET, the risk of untreated occult metastatic PCa lesions is lowered. This could explain the slightly higher TE-FS in our study compared to ADT-FS in previous studies, even though we adopted a broad definition of treatment escalation and included patients with up to five initial lesions. Counterbalancing that was the use of PSMA-PET for restaging in our cohort. This would result in the earlier diagnosis of polymetastatic disease compared with conventional imaging. As polymetastatic disease was an indication for treatment escalation, this could potentially result in a relative reduction in TE-FS compared with other studies.

In our study, the only statistically significant predictor for treatment escalation within two years of initial SBRT was prior ADT. Only six of 27 patients who had received prior ADT remained free of treatment escalation at two years. It is likely that a considerable proportion of these patients had polymetastatic disease at the time they originally commenced ADT, although this cannot be proven as PSMA-PET was not available at that time. We would expect this group to commence ADT sooner after SBRT than the ADT naïve cohort, which is consistent with our results.

Franzese et al. $^{7}$ report worse progression free survival following SBRT for castrationresistant patients compared to castration-sensitive patients, however, no statistically significant difference was observed between these groups in our study in terms of treatment escalation. This may be because the number of castration-resistant men in our study was too low to detect a difference. Nevertheless, five of the thirteen patients in this group in our 
study remained free from treatment escalation at two years, suggesting that SBRT can be a worthwhile treatment in this setting.

The number of oligometastatic PCa lesions considered amenable to MDT remains contentious and this is an important aspect of our study. Most previous studies limit the scope of MDT to three synchronous lesions, given that the likelihood of occult metastases increases as the number of detectable lesions increases. ${ }^{17}$ However, our data shows that treating four to five synchronous PCa lesions with SBRT is just as effective as treating one to three lesions in terms of treatment escalation status at two years and TE-FS. This approach is likely to be most effective when PSMA-PET is used for staging. It should be acknowledged that PSMA-PET is not yet widely available, although its utilisation is rapidly increasing.

While lesion number was not predictive of outcomes following SBRT, our results suggest lesion location to be an important factor. PCa patients with bone metastases typically have a worse prognosis compared to those with locoregional nodal metastases only. ${ }^{18}$ In our study, the rate of freedom from treatment escalation at two years was slightly higher in the nodeonly group (58.4\%) compared to the bone only (47.2\%) groups. For the group receiving SBRT to both bony and nodal sites, the rate of freedom from treatment escalation was notably lower (21.7\%) and the length of TE-FS was shorter (Figure 1C). However, the statistical significance of the association between lesion location and treatment-escalation status remains to be confirmed at the final five-year analysis of these data. Ost et al. ${ }^{4}$ also showed comparable benefits following MDT for patients with nodal versus non-nodal metastases, however a group with both nodal and non-nodal lesions was not available for comparison. 
Importantly, late toxicity was negligible in our study population. Some of our patients have reached four years follow-up post-treatment and there remains no evidence of grade three toxicity. This compares favourably to other systemic treatments for metastatic PCa. Rates of grade three or higher toxicity are reported to be in the order of $30-45 \%$ for ADT alone and this is augmented when adding abiraterone acetate, ${ }^{19}$ docetaxel ${ }^{20}$ or enzalutamide. ${ }^{21}$ For radiotherapy-based MDT, rates of grade three toxicity are typically low. The POPSTAR study reported one (3\%) grade three event (vertebral fracture) using a single 20 Gy fraction. ${ }^{5}$ No grade three or higher toxicities were reported by Decaestecker et al. ${ }^{8}$ (50 Gy in 10 fractions, 30 Gy in 3 fractions), Fanetti et al. ${ }^{6}$ (4-15 Gy in 1-5 fractions) or Ost et al. ${ }^{4}$ (30 Gy in 3 fractions).

Whilst it is true that late radiation toxicity can develop with even longer follow-up, the absence of grade three toxicity up to four years following SBRT in our study suggests that rates of very delayed toxicity will be low, at worst. One contributing factor may have been our relatively hyper-fractionated SBRT schedule of $50 \mathrm{~Gy}$ in 10 fractions. We found this regimen particularly advantageous for treating pelvic lymph node metastases where PTVs were often adjacent to small bowel at the time of simulation and planning. Cone-beam CT verification, which was used for pre-treatment verification for all lymph node metastases, also revealed that the small bowel migrated daily. The chosen fractionation therefore minimised the total dose received by individual anatomical segments of small bowel to a greater degree than would be seen with a more hypo-fractionated or single fraction schedule. Potential differences in safety profile between fractionation schemes may become apparent with longer term follow-up.

There are limitations to our study that should be noted. Firstly, several of the sub-groups in our study, including the prior ADT and concurrent ADT sub-groups, were relatively small and 
the associated analyses should be interpreted with caution. There was a limited group of patients with castration-resistant disease at enrolment, which could have masked a statistically significant interaction between hormone sensitivity and the efficacy of SBRT. Our study did not assess the role of concurrent SBRT and systemic therapy. Future investigation is required to determine whether this will lead to superior outcomes when compared with single modality approaches. Other limitations of our study include the lack of a control arm and the commencement of next-line therapy at the discretion of the treating clinician(s) rather than according to strict criteria. However, using the objective measure of PSA as a surrogate for total cancer burden, we have shown that nearly $25 \%$ of our patients had a lesser cancer burden almost three years after treatment. This demonstrates that despite SBRT being a local treatment, it can have a durable systemic impact.

\section{CONCLUSIONS}

SBRT delays treatment escalation in men with oligometastatic PCa with no associated grade three toxicity. Outcomes for patients with four to five initial lesions were not inferior to patients with one to three lesions. While these analyses represent only interim outcomes, a significant proportion of patients had long-term disease suppression, suggesting the therapeutic index of fractionated SBRT for oligometastatic PCa may be high. Long-term outcomes will be reported after five-years post-SBRT follow-up. Further studies are needed to better quantify the benefits of this approach, the sub-groups who will benefit most and the optimal combination and timing with other systemic treatments.

\section{ACKNOWLEDGEMENTS}

This article is protected by copyright. All rights reserved. 
This study was supported by funding from the Epworth Medical Foundation and the E.J. Whitten Prostate Cancer Foundation.

\section{CONFLICT OF INTEREST STATEMENT}

The authors declare no conflicts of interest.

\section{DATA AVAILABILITY STATEMENT}

The dataset analysed in this study is not publicly available due to participant confidentiality restrictions. Information will be made available by the corresponding author upon reasonable request.

\section{FIGURE LEGENDS}

Figure 1A. Time to treatment escalation stratified by prior ADT status

Figure 1B. Time to treatment escalation stratified by lesion type

Figure 1C. Time to treatment escalation stratified by number of lesions treated

Figure 1D. Time to treatment escalation stratified by if a patient received PSMA-PET-CT at baseline.

Figure 2. Maximal PSA change from baseline following SBRT stratified by $(A)$ lesion number and (B) prior ADT status. A PSA decline was recorded for $75 \%$ of patients. The PSA level of

This article is protected by copyright. All rights reserved. 
six patients fell to an undetectable level following SBRT. Fifteen patients had a maximal PSA change of greater than $+300 \%$ (truncated on plots).

\section{REFERENCES}

1. Cornford P, Bellmunt J, Bolla M, Briers E, De Santis M, Gross T, Henry AM, Joniau S, Lam TB, Mason MD, van der Poel HG, van der Kwast TH, Rouviere O, Wiegel T, Mottet N. EAU-ESTRO-SIOG guidelines on prostate cancer. Part II: Treatment of relapsing, metastatic, and castration-resistant prostate cancer. Eur Urol 2017; 71: $630-642$

2. Hellman S, Weichselbaum RR. Oligometastases. J Clin Oncol 1995; 13: 8-10

3. Giannarini G, Fossati N, Gandaglia G, Cucchiara V, Ficarra V, Mirone V, Montorsi F, Briganti A. Will image-guided metastasis-directed therapy change the treatment paradigm of oligorecurrent prostate cancer? Eur Urol 2018; 74: 131-133

4. Ost P, Reynders D, Decaestecker K, Fonteyne V, Lumen N, De Bruycker A, Lambert B, Delrue L, Bultijnck R, Claeys T, Goetghebeur E, Villeirs G, De Man K, Ameye F, Billiet I, Joniau S, Vanhaverbeke F, De Meerleer G. Surveillance or metastasisdirected therapy for oligometastatic prostate cancer recurrence: A prospective, randomized, multicenter phase II trial. J Clin Oncol 2018; 36: 446-453

5. Siva S, Bressel M, Murphy DG, Shaw M, Chander S, Violet J, Tai KH, Udovicich C, Lim A, Selbie L, Hofman MS, Kron T, Moon D, Goad J, Lawrentschuk N, Foroudi F. Stereotactic abative body radiotherapy (SABR) for oligometastatic prostate cancer: A prospective clinical trial. Eur Urol 2018; 74: 455-462

This article is protected by copyright. All rights reserved. 
6. Fanetti G, Marvaso G, Ciardo D, Rese A, Ricotti R, Rondi E, Comi S, Cattani F, Zerini D, Fodor C, de Cobelli O, Orecchia R, Jereczek-Fossa BA. Stereotactic body radiotherapy for castration-sensitive prostate cancer bone oligometastases. Med Oncol 2018; 35: 75

7. Franzese C, Zucali PA, Di Brina L, D'Agostino G, Navarria P, Franceschini D, Santoro A, Scorsetti M. The efficacy of stereotactic body radiation therapy and the impact of systemic treatments in oligometastatic patients from prostate cancer. Cancer Med 2018; 7: 4379-4386

8. Decaestecker K, De Meerleer G, Lambert B, Delrue L, Fonteyne V, Claeys T, De Vos F, Huysse W, Hautekiet A, Maes G, Ost P. Repeated stereotactic body radiotherapy for oligometastatic prostate cancer recurrence. Radiat Oncol 2014; 9: 135

9. Compton C, Byrd D, Garcia-Aguilar J, Kurtzman S, Olawaiye A, Washington M, eds. AJCC cancer staging atlas. A companion to the seventh editions of the AJCC cancer staging manual and handbook, 2nd ed. New York: Springer-Verlag, 2012. 637p

10. Hsueh EC, DeBloom JR, Lee J, Sussman JJ, Covington KR, Middlebrook B, Johnson C, Cook RW, Slingluff CL, McMasters KM. Interim analysis of survival in a prospective, multi-center registry cohort of cutaneous melanoma tested with a prognostic 31-gene expression profile test. J Hematol Oncol 2017; 10: 152

11. Hosmer D, Lemeshow S, Sturdivant R. Applied logistic regression, 3rd ed. Hoboken: Wiley, 2013. 528p

12. Hosmer D, Lemeshow S, May S. Applied survival analysis: regression modelling of time-to-event, 2nd ed. Hoboken: Wiley, 2008. 401p

This article is protected by copyright. All rights reserved. 
13. Gedye C, Wheatley-Price P, Boutros PC, Chia PL, John T. Current and evolving methods to visualize biological data in cancer research. J Natl Cancer Inst 2016; 108 : djw031

14. Cimadamore A, Cheng M, Santoni M, Lopez-Beltran A, Battelli N, Massari F, Galosi $A B$, Scarpelli M, Montironi R. New prostate cancer targets for diagnosis, imaging, and therapy: Focus on prostate-specific membrane antigen. Front Oncol 2018; 8: 653

15. Afshar-Oromieh A, Zechmann CM, Malcher A, Eder M, Eisenhut M, Linhart HG, Holland-Letz T, Hadaschik BA, Giesel FL, Debus J, Haberkorn U. Comparison of PET imaging with a (68)Ga-labelled PSMA ligand and (18)F-choline-based PET/CT for the diagnosis of recurrent prostate cancer. Eur J Nucl Med Mol Imaging 2014; 41: $11-20$

16. Fanti S, Minozzi S, Antoch G, Banks I, Briganti A, Carrio I, Chiti A, Clarke N, Eiber M, De Bono J, Fizazi K, Gillessen S, Gledhill S, Haberkorn U, Herrmann K, Hicks RJ, Lecouvet F, Montironi R, Ost P, O'Sullivan JM, Padhani AR, Schalken JA, Scher HI, Tombal B, van Moorselaar RJA, Van Poppel H, Vargas HA, Walz J, Weber WA, Wester HJ, Oyen WJG. Consensus on molecular imaging and theranostics in prostate cancer. Lancet Oncol 2018; 19: E696-E708

17. Kendal WS. Oligometastasis as a predictor for occult disease. Math Biosci 2014; 251: $1-10$

18. Gandaglia G, Karakiewicz PI, Briganti A, Passoni NM, Schiffmann J, Trudeau V, Graefen M, Montorsi F, Sun M. Impact of the site of metastases on survival in patients with metastatic prostate cancer. Eur Urol 2015; 68: 325-334

19. Fizazi K, Tran N, Fein L, Matsubara N, Rodriguez-Antolin A, Alekseev BY, Ozguroglu M, Ye D, Feyerabend S, Protheroe A, De Porre P, Kheoh T, Park YC, Todd MB, Chi

This article is protected by copyright. All rights reserved. 
$\mathrm{KN}$. Abiraterone plus prednisone in metastatic, castration-sensitive prostate cancer. N Engl J Med 2017; 377: 352-360

20. James ND, Sydes MR, Clarke NW, Mason MD, Dearnaley DP, Spears MR, Ritchie AW, Parker CC, Russell JM, Attard G, de Bono J, Cross W, Jones RJ, Thalmann G, Amos C, Matheson D, Millman R, Alzouebi M, Beesley S, Birtle AJ, Brock S, Cathomas R, Chakraborti P, Chowdhury S, Cook A, Elliott T, Gale J, Gibbs S, Graham JD, Hetherington J, Hughes R, Laing R, McKinna F, McLaren DB, O'Sullivan JM, Parikh O, Peedell C, Protheroe A, Robinson AJ, Srihari N, Srinivasan R, Staffurth J, Sundar S, Tolan S, Tsang D, Wagstaff J, Parmar MK. Addition of docetaxel, zoledronic acid, or both to first-line long-term hormone therapy in prostate cancer (STAMPEDE): Survival results from an adaptive, multiarm, multistage, platform randomised controlled trial. Lancet 2016; 387: 1163-1177

21. Beer TM, Armstrong AJ, Rathkopf DE, Loriot $\mathrm{Y}$, Sternberg CN, Higano CS, Iversen P, Bhattacharya S, Carles J, Chowdhury S, Davis ID, de Bono JS, Evans CP, Fizazi K, Joshua AM, Kim CS, Kimura G, Mainwaring P, Mansbach H, Miller K, Noonberg SB, Perabo F, Phung D, Saad F, Scher HI, Taplin ME, Venner PM, Tombal B. Enzalutamide in metastatic prostate cancer before chemotherapy. $\mathrm{N}$ Engl J Med 2014; 371: 424-433

This article is protected by copyright. All rights reserved. 
Table 1. Patient Characteristics

\begin{tabular}{|c|c|}
\hline Characteristic & All patients $(n=199)$ \\
\hline \multicolumn{2}{|l|}{ Age at baseline } \\
\hline Mean (SD) & $67.4(6.5)$ \\
\hline \multicolumn{2}{|l|}{ Gleason score } \\
\hline 6 & $4(2.0)$ \\
\hline 7 & $111(55.8)$ \\
\hline 8 & $15(7.5)$ \\
\hline 9 and 10 & $62(31.2)$ \\
\hline Missing & $7(3.5)$ \\
\hline \multicolumn{2}{|l|}{$P S A$ at baseline $(\mathrm{ng} / \mathrm{mL})$} \\
\hline Median (IQR) & $1.8(0.8-4.6)$ \\
\hline Missing & $6(3.0)$ \\
\hline \multicolumn{2}{|l|}{ Type of primary therapy } \\
\hline Radical prostatectomy & $185(93.0)$ \\
\hline External beam radiotherapy & $9(4.5)$ \\
\hline Brachytherapy & $3(1.5)$ \\
\hline Not stated & $2(1.0)$ \\
\hline \multicolumn{2}{|l|}{ Prior $A D T$} \\
\hline No & $152(76.4)$ \\
\hline Yes & $33(16.6)$ \\
\hline Concurrent & $14(7.0)$ \\
\hline \multicolumn{2}{|l|}{ Castration sensitivity: } \\
\hline Resistant & $14(7.0)$ \\
\hline Sensitive & $185(93.0)$ \\
\hline \multicolumn{2}{|c|}{ Number of initial oligometastatic lesions } \\
\hline 1 & $81(40.7)$ \\
\hline 2 & $50(25.1)$ \\
\hline 3 & $34(17.1)$ \\
\hline 4 & $24(12.1)$ \\
\hline 5 & $10(5.0)$ \\
\hline \multicolumn{2}{|l|}{ Site of initial oligometastatic lesions } \\
\hline Bone only & $45(22.6)$ \\
\hline Node only & $126(63.3)$ \\
\hline Bone and node & $24(12.1)$ \\
\hline Other & $4(2.0)$ \\
\hline
\end{tabular}

Time between primary therapy and SBRT (years)

This article is protected by copyright. All rights reserved. 
Data are presented as no. (\%) unless otherwise indicated.

Abbreviations: ADT, androgen deprivation therapy; IQR, inter quartile range; PSA, prostate specific antigen; SBRT, stereotactic body radiotherapy; SD, standard deviation.

Table 2. Indications for escalating treatment within two-years of SBRT

\begin{tabular}{|c|c|c|c|c|}
\hline $\begin{array}{l}\text { Type of } \\
\text { treatment }\end{array}$ & No. (\%) & Reason & No. (\%) & $\begin{array}{l}\text { Median (IQR) PSA } \\
\text { level at time of TE* } \\
(\mathrm{ng} / \mathrm{mL})\end{array}$ \\
\hline \multirow[t]{3}{*}{ ADT } & 75 (88.2) & Rising PSA & $43(57.3)$ & $8.0(3.8-14.5)$ \\
\hline & & Polymetastatic disease & $25(33.3)$ & $4.2(2.0-8.5)$ \\
\hline & & $\begin{array}{l}\text { Oligometastatic disease } \\
\text { - overlap with previous } \\
\text { RT fields }\end{array}$ & $7(9.4)$ & $3.6(2.7-5.4)$ \\
\hline Chemotherapy & $5(5.9)$ & Polymetastatic disease & $5(100.0)$ & $11.6(5.8-12.0)$ \\
\hline Palliative RT & $5(5.9)$ & Polymetastatic disease & $5(100.0)$ & $8.1(7.4-9.7)$ \\
\hline Total & $85(100.0 \%)$ & & & $6.5(3.1-12.8)$ \\
\hline
\end{tabular}

*The median (IQR) time between last recorded PSA and treatment escalation was $22(10-40)$ days.

Abbreviations: ADT, androgen deprivation therapy; PSA, prostate specific antigen; RT, radiotherapy; TE, treatment escalation

This article is protected by copyright. All rights reserved. 


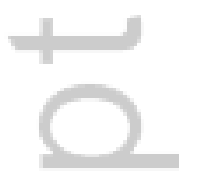

This article is protected by copyright. All rights reserved. 
Table 3. Sub-group analyses for treatment-escalation status two-years post-SBRT

\begin{tabular}{|c|c|c|c|c|}
\hline \multirow[t]{2}{*}{ Characteristics } & \multirow{2}{*}{$\begin{array}{c}\text { Treatment } \\
\text { escalation } \\
\text { free } \\
N(\%)\end{array}$} & \multicolumn{3}{|c|}{ Relationship with patient characteristic } \\
\hline & & OR & $95 \% \mathrm{Cl}$ & $p$-value \\
\hline Age at baseline & - & 0.99 & $0.94-1.03$ & 0.574 \\
\hline \multicolumn{5}{|l|}{ Gleason score } \\
\hline 6 or $7(n=106)$ & $57(53.8)$ & Ref & & \\
\hline $8(n=13)$ & $7(53.9)$ & 1.003 & $0.32-3.18$ & 0.996 \\
\hline 9 and $10(n=52)$ & $23(44.2)$ & 0.68 & $0.35-1.33$ & 0.261 \\
\hline PSA at baseline & --- & 0.94 & $0.88-1.003$ & 0.063 \\
\hline \multicolumn{5}{|l|}{ Type of primary therapy } \\
\hline$R P(n=166)$ & $84(50.6)$ & Ref & & \\
\hline EBRT $(n=6)$ & $5(83.3)$ & 4.88 & $0.56-42.68$ & 0.152 \\
\hline \multicolumn{5}{|l|}{ Initial staging with PSMA-PET-CT } \\
\hline No $(n=38)$ & $17(44.7)$ & Ref & & \\
\hline Yes $(n=138)$ & $74(53.6)$ & 1.43 & $0.69-2.95$ & 0.334 \\
\hline \multicolumn{5}{|l|}{ Prior ADT } \\
\hline No $(n=136)$ & $79(58.1)$ & Ref & & \\
\hline Yes $(n=27)$ & $6(22.2)$ & 0.21 & $0.08-0.54$ & 0.001 \\
\hline Concurrent $(n=13)$ & $6(46.1)$ & 0.62 & $0.20-1.94$ & 0.173 \\
\hline \multicolumn{5}{|l|}{ Castration sensitivity } \\
\hline Resistant $(n=13)$ & $5(38.5)$ & Ref & & \\
\hline Sensitive $(n=163)$ & $86(52.8)$ & 1.78 & $0.56-5.69$ & 0.326 \\
\hline \multicolumn{5}{|l|}{$\begin{array}{l}\text { Number of initial oligometastatic } \\
\text { lesions }\end{array}$} \\
\hline $1-3(n=145)$ & $75(51.7)$ & Ref & & \\
\hline $4-5(n=31)$ & $16(51.6)$ & 0.996 & $0.46-2.16$ & 0.991 \\
\hline \multicolumn{5}{|l|}{$\begin{array}{l}\text { Site of initial oligometastatic } \\
\text { lesions }\end{array}$} \\
\hline Bone only $(n=36)$ & $17(47.2)$ & Ref & & \\
\hline Node only $(n=113)$ & $66(58.4)$ & 1.57 & $0.74-3.33$ & 0.241 \\
\hline Bone and Node $(n=23)$ & $5(21.7)$ & 0.31 & $0.09-1.02$ & 0.054 \\
\hline Time between primary therapy & - & 1.0 & $1.0-1.0002$ & 0.905 \\
\hline
\end{tabular}

This article is protected by copyright. All rights reserved. 
and SBRT (years)

Abbreviations: ADT, androgen deprivation therapy; $\mathrm{Cl}$, confidence interval; EBRT, external beam radiotherapy; OR, odds ratio; PSA, prostate specific antigen; Ref, reference category; RP, radical prostatectomy; SBRT, stereotactic body radiotherapy.

This article is protected by copyright. All rights reserved. 


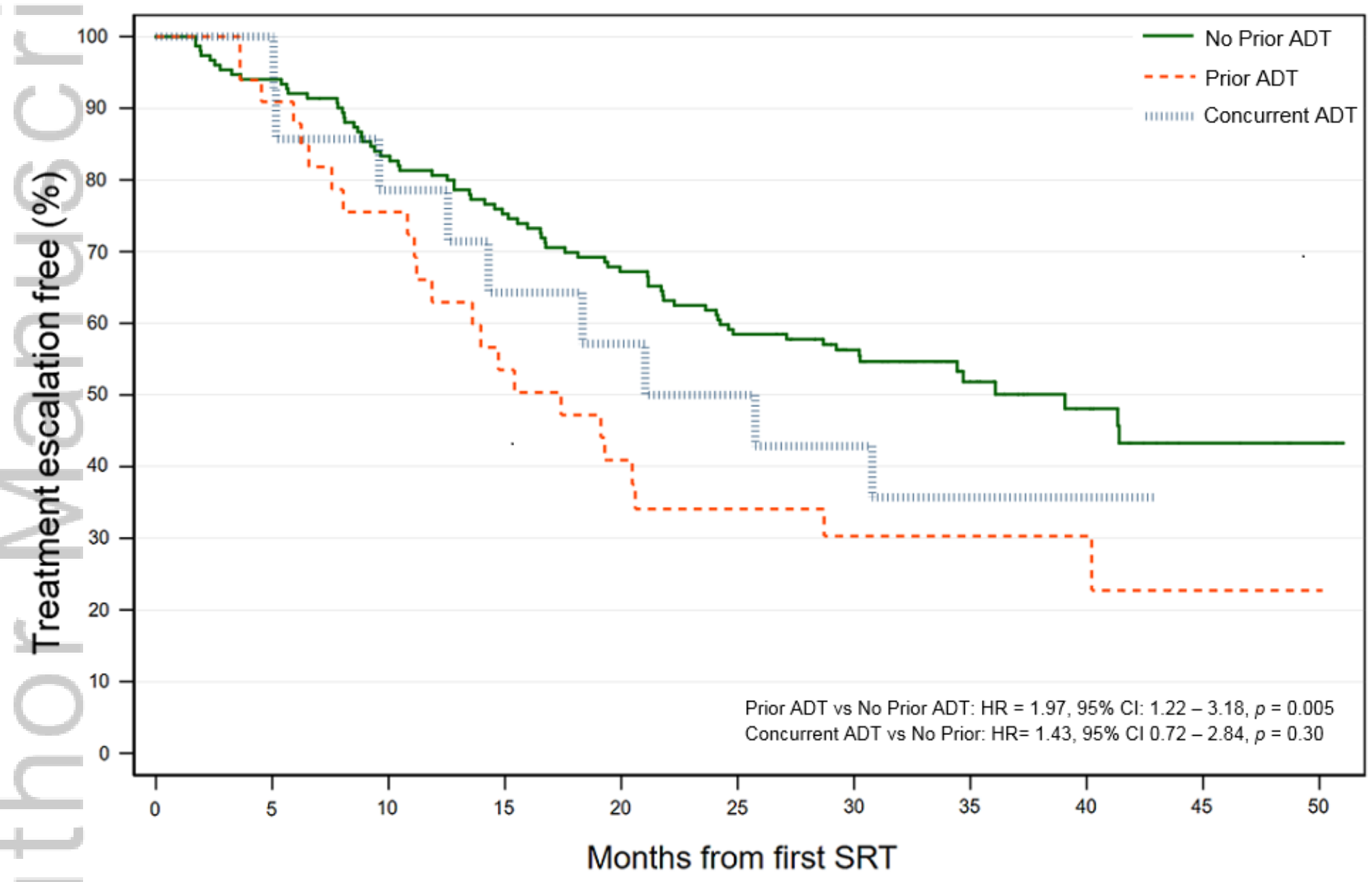

IJC_32509_Figure 1A.tif

This article is protected by copyright. All rights reserved. 


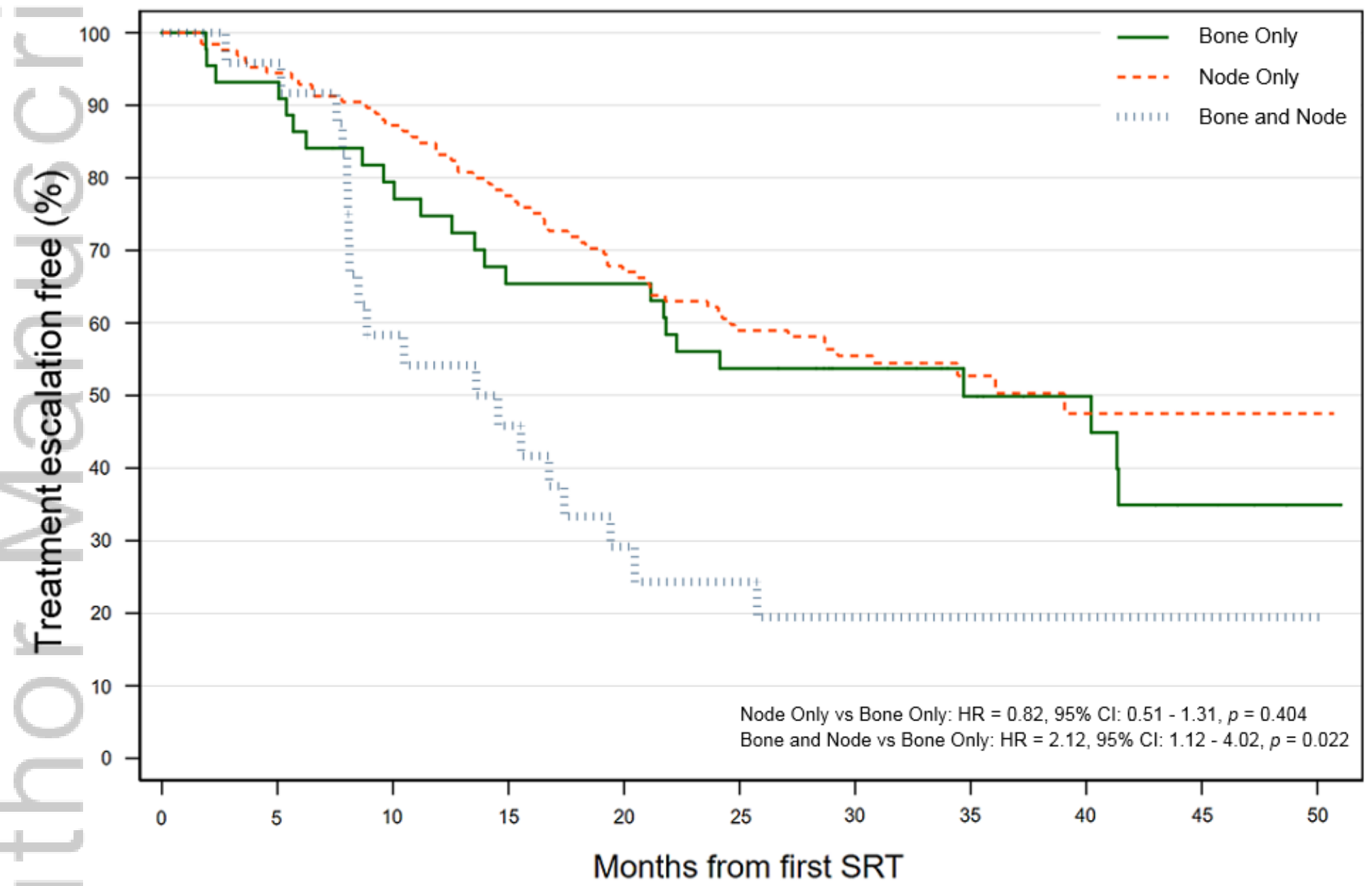

IJC_32509_Figure 1B.tif

This article is protected by copyright. All rights reserved. 


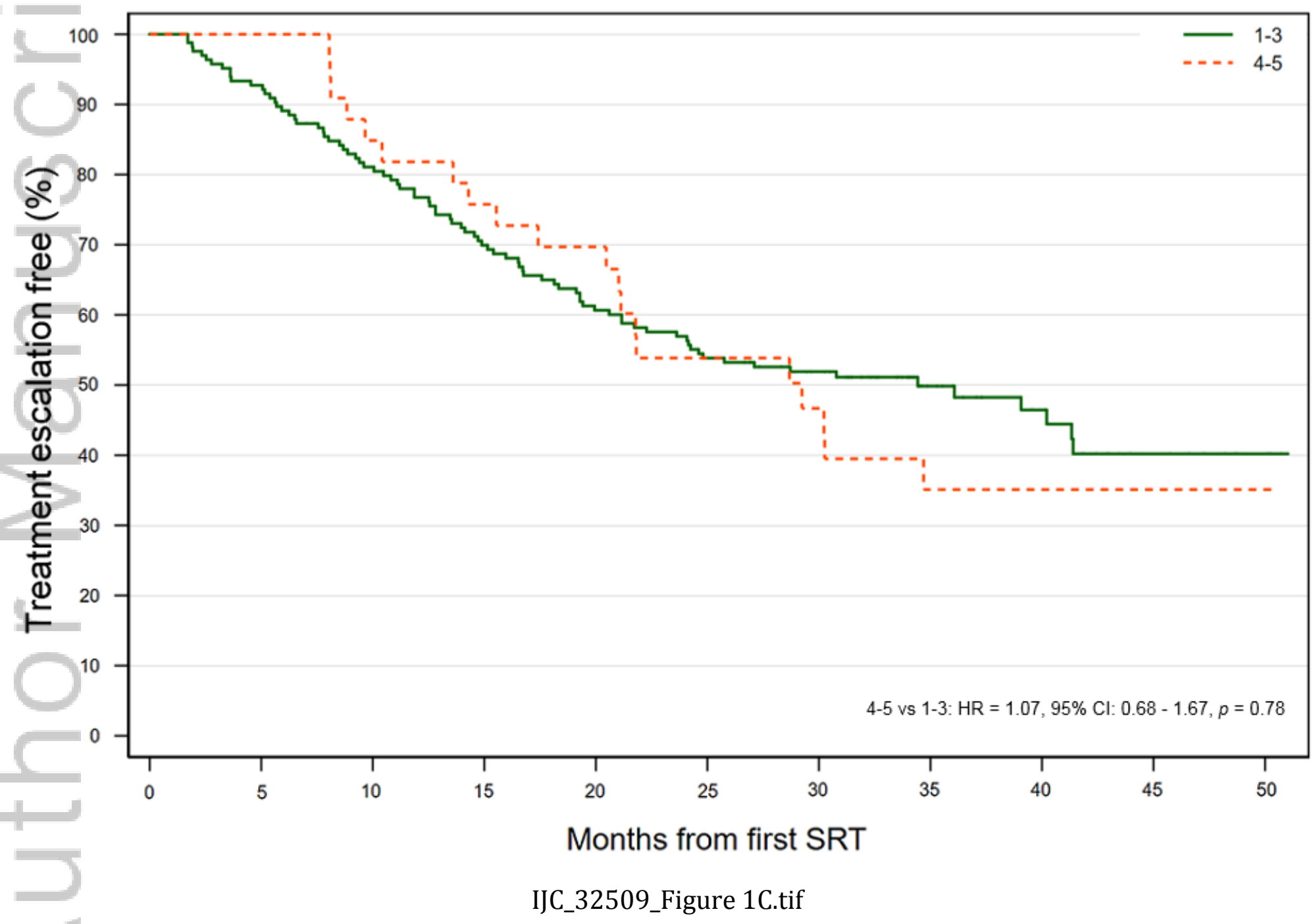

This article is protected by copyright. All rights reserved. 


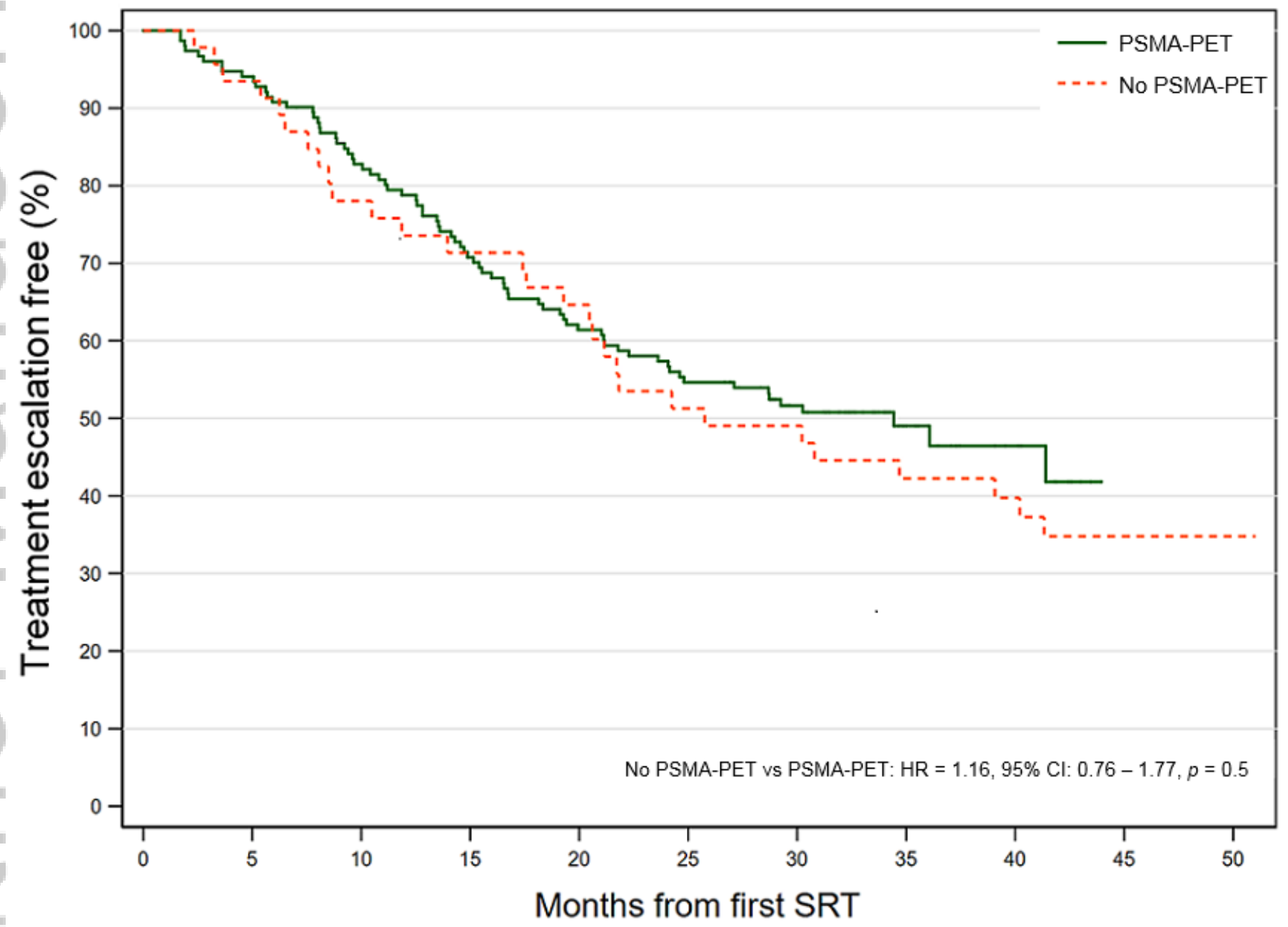

IJC_32509_Figure 1D.tif

This article is protected by copyright. All rights reserved. 


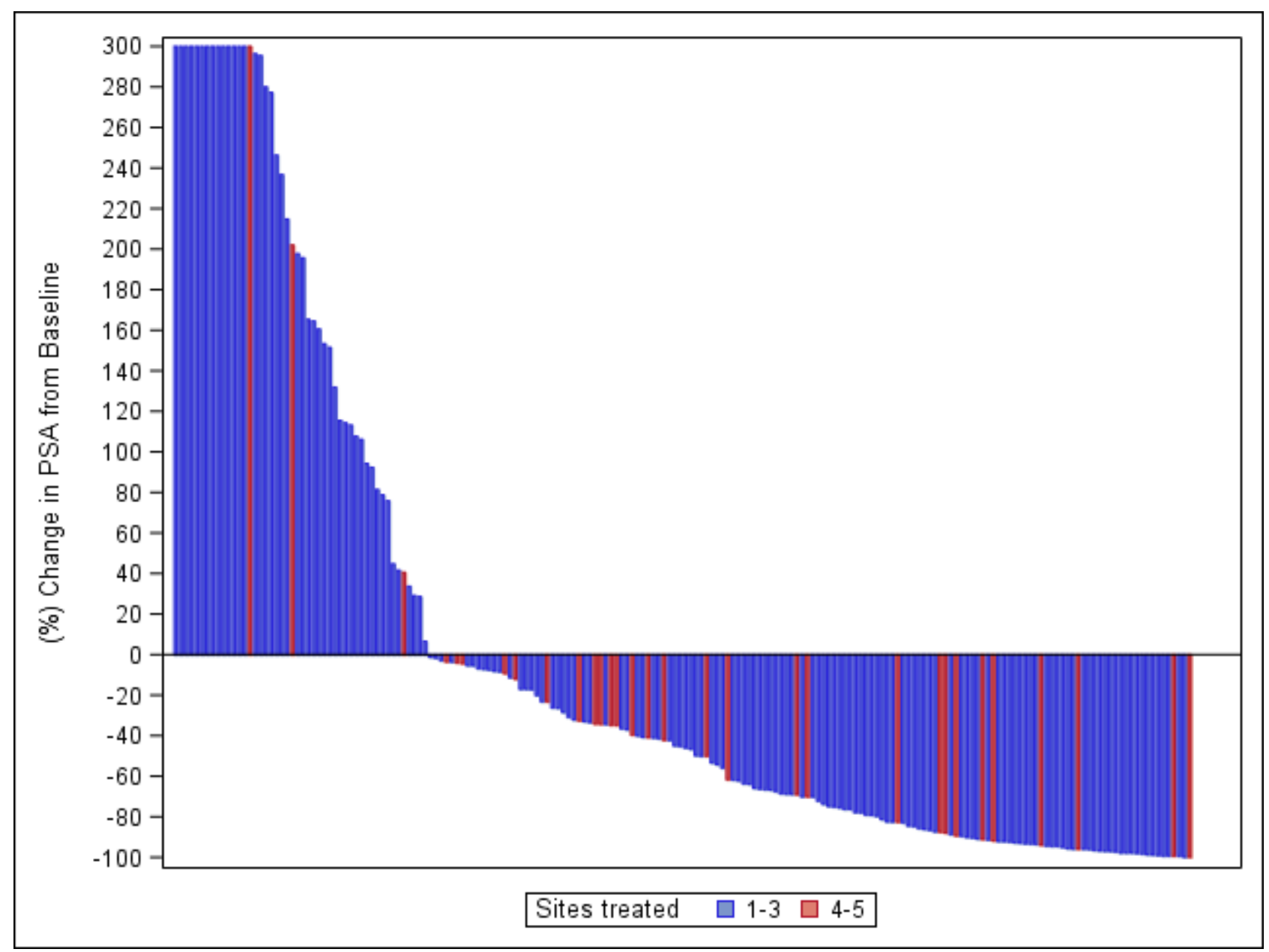

IJC_32509_Figure 2A.tif

This article is protected by copyright. All rights reserved. 


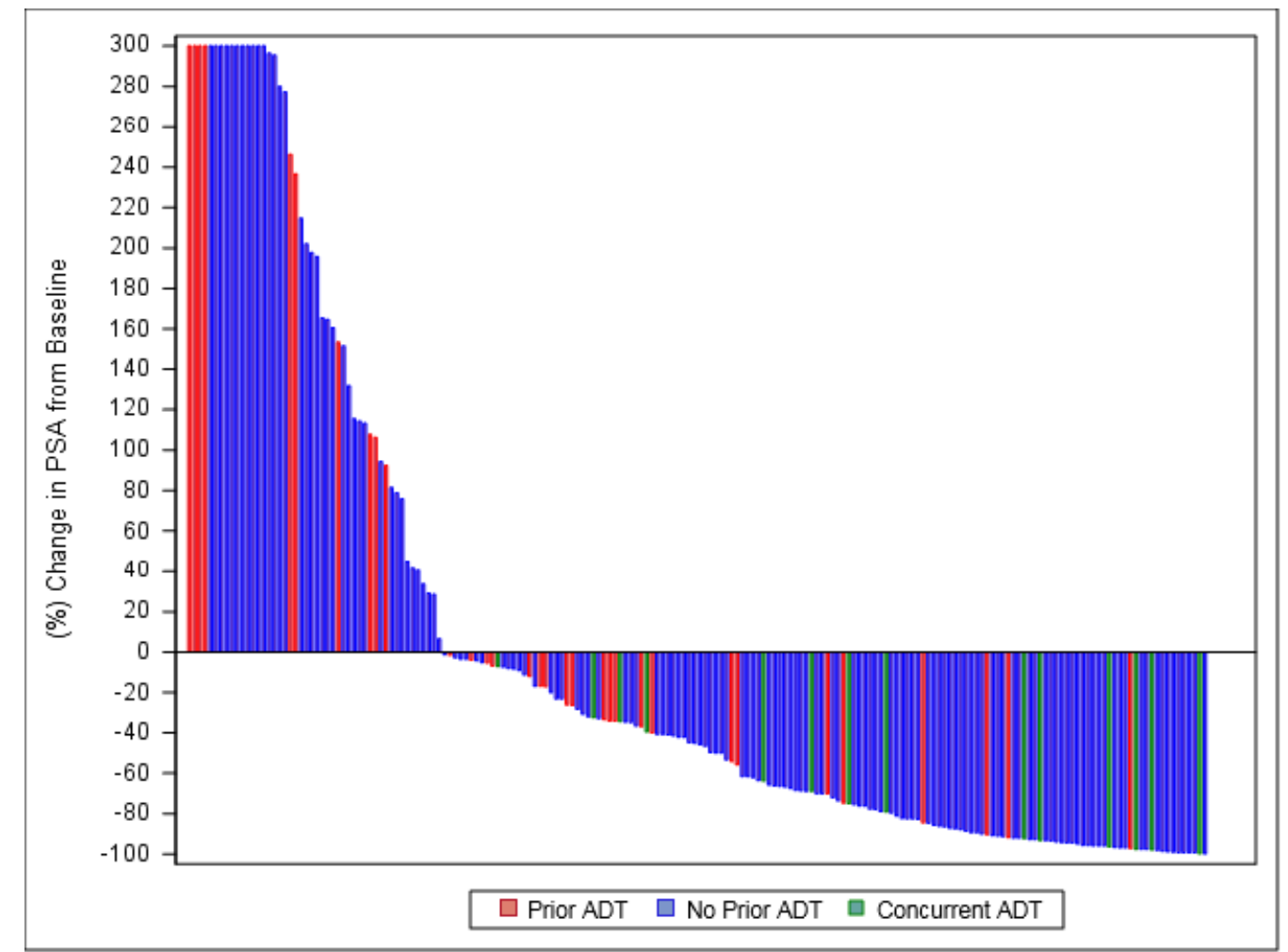

IJC_32509_Figure 2B.tif

This article is protected by copyright. All rights reserved. 
Novelty \& Impact Statement: IJC-19-1114.R1

Metastasis-directed therapy (MDT), involving surgery or stereotactic ablative radiotherapy, is a promising alternative treatment strategy for prostate cancer patients with metastatic disease. It remains unclear, however, which subsets of patients most benefit from MDT. Here, interim analysis of a large prospective trial involving fractionated stereotactic body radiotherapy (SBRT) for prostate cancer patients with up to five synchronous oligometastases shows that two years following SBRT, about half of patients did not require treatment escalation. In addition, nearly one-quarter of patients had prostatespecific antigen levels below baseline. The findings highlight the promise of SBRT for long-term suppression of oligometastatic prostate cancer. 


\section{University Library}

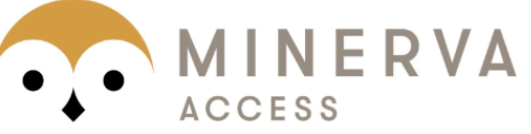

A gateway to Melbourne's research publications

Minerva Access is the Institutional Repository of The University of Melbourne

Author/s:

Bowden, P;See, AW;Frydenberg, M;Haxhimolla, H;Costello, AJ;Moon, D;Ruljancich,

P;Grummet, J;Crosthwaite, A;Pranavan, G;Peters, JS;So, K;Gwini, SM;McKenzie, DP;Nolan, S;Smyth, LML;Everitt, C

Title:

Fractionated stereotactic body radiotherapy for up to five prostate cancer oligometastases: Interim outcomes of a prospective clinical trial

Date:

2020-01-01

\section{Citation:}

Bowden, P., See, A. W., Frydenberg, M., Haxhimolla, H., Costello, A. J., Moon, D., Ruljancich, P., Grummet, J., Crosthwaite, A., Pranavan, G., Peters, J. S., So, K., Gwini, S. M., McKenzie, D. P., Nolan, S., Smyth, L. M. L. \& Everitt, C. (2020). Fractionated stereotactic body radiotherapy for up to five prostate cancer oligometastases: Interim outcomes of a prospective clinical trial. INTERNATIONAL JOURNAL OF CANCER, 146 (1), pp.161-168. https://doi.org/10.1002/ijc.32509.

Persistent Link:

http://hdl.handle.net/11343/286054 